\title{
Les éléments de réponse aux rétinoïdes, à l'acide rétinoïque, à la vitamine $D$ et aux hormones thyroïdiennes
}

En 1990, nous résumions ce qui était connu des éléments de réponse aux hormones liant des protéines appartenant à la super famille des récepteurs nucléaires $\left(\mathrm{m} / \mathrm{s}, n^{\circ} 3\right.$, vol. 6, p. 307). Depuis ce rappel, de nouveaux récepteurs ont été caractérisés, leurs sites de fixation spécifique à l'ADN (c'est-à-dire les éléments de réponse aux hormones, HRE) ont été mieux définis et la structure précise des complexes entre ces récepteurs et leurs cibles $\mathrm{ADN}$ a été étudiée en détail. Notamment, plusieurs récepteurs cellulaires de l'acide rétinoïque ( $\mathrm{RAR}$, retinoid acid receptor) ont été mis en évidence: $\operatorname{RAR} \alpha, \operatorname{RAR} \beta$, RAR $\gamma$ et RXR. Ce dernier récepteur, décrit en 1990 par l'équipe de R.M.Evans (La Jolla, CA, USA) fixe l'acide rétinoïque, mais aussi, avec une bonne affinité, d'autres rétinoïdes. La séquence optimale de ses cibles d'ADN semblait également différente de celles des autres RAR [1]. En 1991, K. Umesomo et al., également de l'équipe de R.M. Evans, montraient que les récepteurs de l'acide rétinoïque se fixaient avec une très bonne affinité à des répétitions directes de la séquence AGGTCA, chacune des répétitions étant séparée de cinq nucléotides. Ces mêmes auteurs montraient que la longueur de cette séquence intercalaire gouvernait la spécificité de cet élément d'ADN. Alors qu'un espacement de cinq nucléotides entre les deux éléments répétés produit un élément de réponse à l'acide rétinoïque RARE $\mathrm{m} / \mathrm{s} n^{\circ} 8$, vol. 7 , octobre 91 (retinoic acid response element), un espacement de quatre nucléotides engendre un TRE (thyroid hormone response element), trois nucléotides donnant un VDRE (vitamin D response element) [2]. D.J. Mangelsdorf, toujours du laboratoire de R.M.Evans, démontre maintenant que la molécule $\mathrm{RXR}$ se fixe avec une très particulière affinité à un élément de réponse RXRE de séquence AGGTCA-N-AGGTCA, c'est-à-dire comportant les deux répétitions classiques séparées d'un seul nucléotide. Plusieurs éléments de cette répétition sont notés en amont du gène codant pour la protéine de liaison du rétinol de type 2 (CRBP2, cellular retinol binding protein 2) qui est une protéine-clé de l'absorption intestinale de la vitamine $A$. Le gène CRBP2 est considérablement stimulé par l'acide rétinoïque en présence du récepteur $\mathrm{RXR}$, mais non des récepteurs de type RAR. En réalité, les protéines $\mathrm{RXR}$ et RAR se fixent les unes et les autres à l'élément RXRE du gène CRBP2, mais seule la fixation du complexe rétinoïde/RXR induit une activation transcriptionnelle, alors que la fixation de récepteurs RAR a un effet inhibiteur. Ces résultats sont remarquables à deux titres au moins.

1. Ils étendent notre connaissance des déterminants de la spécificité des éléments de réponse aux hormones (et cela est peut-être valable pour d'autres types de sites de fixation de facteurs de transcription). Ici, la taille d'un segment intercalaire entre les deux hexanucléotides directement répétés, AGGTCA, gouverne le type de réponse hormonale conférée. La signification d'un espacement de 1 , 3,4 et 5 nucléotides est maintenant connue; quel type de réponse confère un espacement de deux nucléotides?

2. Il apparaît qu'existent des mécanismes d'une considérable diversification des effets gouvernés par l'acide rétinoïque et d'autres rétinoïdes. Cela vient de l'expression dans des tissus, à des stades différents du développement, des différents récepteurs, et aussi de la variabilité des effets selon les séquences d'ADN reconnues. Des travaux ultérieurs diront si les différents rétinoïdes ont quelque spécificité de fixation pour les protéines RAR et RXR, contrôlant alors des processus de régulation distincts.

A.K.

1. Mangelsdorf DJ, Ong ES, Dyck JA, Evans RM. A nuclear receptor that identifies a novel retinoic acid response pathway. Nature 1990 ; 345: 224-9.

2. Umesomo $\mathrm{K}$, Giguere $\mathrm{V}$, Glass $\mathrm{CK}$, Rosenfeld MG, Evans RM. Retinoic acid and thyroid hormone induce gene expression through a common responsive element. Cell $1991 ; 65: 1255-66$.

3. Mangelsdorf DJ, Umesomo K, Kliewer SA, Borgmeyer U, Ong ES, Evans RM. A direct repeat in the cellular retinol binding protein type II gene confers differential regulation by RXR and RAR. Cell 1991; 66 : 555-6.

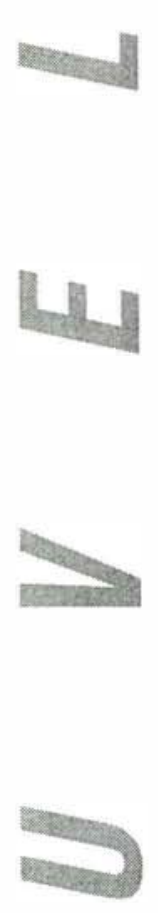

(n)

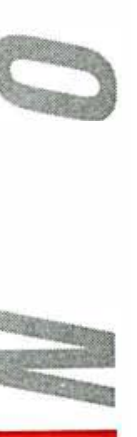

